\title{
Artificial Intelligence on Future Aspects
}

\section{(How AI Will Impact in 2030)}

\author{
Dr.Indradeep Verma ${ }^{1}$, Dr. K. Rama Krishna ${ }^{2}$, Divya Sen $^{3}$, Jyoti Kumari Prasad ${ }^{4}$ \\ ${ }^{1}$ Associate Professor, IIMT College of-Engineering, Greater Noida, U.P \\ ${ }^{2}$ Professor, Department of CSE, IIMT College of-Engineering, Greater Noida, U.P \\ ${ }^{3}$ U.G Student, Department of CSE, IIMT College of -Engineering, Greater Noida, U.P \\ ${ }^{4}$ U.G Student, Department of CSE, IIMT College of -Engineering, Greater Noida, U.P
}

\begin{abstract}
As Artificial Intelligence(AI) is emerging in this century,it can be seen as it is going to take most of the humans' tasks soon.Artificial Intelligence is widely used in all the fields whether it is medical field,research field,automatic vehicle system,Business models of market,weather forecasting and much more.If the future prospects of AI to be highlighted, then the main focus are on how AI will impact on lifestyle of people and how will our society and industries going to change.In this research paper,the AI growth and its applications will be highlighted in three phases.In the first phase the past events of AI and its growth is discussed,the second phase covers the present event and applications of AI and in the last phase,the future(after 10 years) aspects and its applications will be highlighted.As the world is growing in the fast pace and the information technology field is shaping every context of market and research.
\end{abstract}

Keywords

Artificial Intelligence,Automation,Machine Learning,Deep Learning,Digitization

\section{INTRODUCTION:}

\section{Problem Statement-}

The world is changing so fast and it develop and grows in each bit of time.Technology has a very long evolving process since a century ago,it made and create thousands of applications and gadgets which has turned the world and imagination of researchers and scientists in a new direction.

Before 2 centuries ago, no one imagined a world having something which has camera and flying in the air known as "Drones".Imagination of people were not as vast as like present scenario at that point of time.

Technologies are emerging very fast nowadays viz. Artificial Intelligence(AI) ,Cloud Computing, Internet of Things(IOT), Data Science, Big Data and Blockchain are the technologies which are changing the way we live,research and work on ourselves. The more world will move towards the AI and Machine Learning,the more market will move towards the Automation. AI is impacting the present global market and much of fields and replacing the tasks which are done by Human and shaping the business contexts and research with AI.In context with Artificial Intelligence the researchers havedivided two groups on the idea of AI in future aspect.First group defines AI as a disruptive methodology, many have predicted in a negative way that it will be getting to replace the human workers job by robots. The other view is AI will bring more advancement and automation in the computer science field and will offer more jobs than it displaces, AI can also create new tools for entrepreneurs and it will create a next level modernity of business and other sectors that we cannot imagine now.It is often seen that AI isn't only creating new jobs while it will also help people to perform much better on their job.At the World Economic Forum in Davos,Paul Daugherty,Accenture's Chief Technology and Innovation Officer summed that -"Humans plus machine equals superpowers".The optimistic view 
on $\mathrm{AI}$ is going to be more realistic,smarter and innovative.It will result digitization within the world and it might ease human-machine interactions with many of developing hyper networking and hyper automation.

Andrew Ng., co-founder Google Brain; former vice chairman and Chief scientist of Baidu;co-founder and co-chairman of Coursera and an adjust professor at Stanford University said in 2017 at Stanford MSx(Master of Science in Management for Experimental Leaders) Program.

"As Electricity transformation changed everything 100 years ago,Today I even have a troublesome time thinking of an industry that I don't think AI will transform within subsequent several years". The worth and weight of this statement is more considerable because Professor Andrew Ng. is one of the top thinkers and researchers in AI and Machine Learning(Marr 2017).AI features a prominent and important place within the lists of emerging technologies because of its capability and speed it will force other industries to develop themselves as AI based industry.

Artificial Intelligence are going to be 'vastly smarter' than Humans and would overtake us by 2025. This prediction done by Elon Mask, Tesla and SpaceX CEO.

\section{Research Objectives:}

The research paper highlights the impact of AI and Machine Learning on future aspects and how it leads the world from current scenario to more advanced and innovative in the upcoming decade.The objective focuses on howtechnology will make it adopted by Humans and transform their way of living. Some objectives are as follows:-

- How the existence of AI has changed the way of thinking and imagination of the people and how it impacted on the society in last century?

- What are the fields and markets based on AI getting benefitted from its advancements?

- AI has always been a topic of discussion among its thinkers and researchers for its good as well as bad.How the expansion of AI may lead destruction in the world?

- How AI will be going to impact on ourselves after 10years (a decade)?

\section{Definitions:}

Artificial Intelligence: - is a branch of computer science which believes to give machines human resemblance to facilitate human tasks in a better way.

Automation: -It is a process where Machines are operating and performing tasks automatically or with minimum human intervention.

Machine Learning: -It is a sub field of AI where the algorithms have the capability to learn and improve themselves through past experiences or historical data.

Deep Learning: -is a subset of Machine Learning where multiple artificial neural networks, algorithms inspired by the functioning of Human Brain and learn from large amounts of data.

Digitization: -A process of converting analog information into digital form(i.e., in the form of zeros or ones).

\section{Existence of AI (Past Events):}

In the 18th century, machines can actually think, and intelligent Robots concept was just a part of myths, imagination and fiction. But the researchers and logic theorists were trying to make it possible in reality by holding an open discussion with some great thinkers and professors during conferences. Before 7 decades ago, a term "Artificial Intelligence" coined by John McCarthy in 1956 during a conference but the concept that machines can think came into existence much before that. When the first computer was available on the market then the concept of 'logic' known to the people and that was the unofficial existence of Artificial Intelligence.

AI has a long journey of evolvement; it ranges from machines which are truly capable of thinking to search algorithms used to play board games. During the initial years of AI some researchers proposed these thinking capabilities of machines in various seminars and after that Alan Turing wrote a paper that how can machines be able to perform tasks such as humans do, how machines have ability to do intelligent things like playing chess[Turing 50]. 
The surge of AI began with some major design goals described as follows-

- A programming language 'Lisp' was developed for the purpose. Knowledge representation for the machine's interaction with Humans and real world and how machines needed to identify real world objects, languages and people like humans do.

- Train machines to perform in accordance with mental tasks like playing chess, proving Mathematical Theorems.

- Teach machines to know and adopt the world around we live in to plan and navigate and the reason behind that to make machines autonomous.

- Train machines to stimulate like humans that they perceive to sense, feel, hear ,taste and sight.

- Get Ready machines to train on general intelligence like emotional intelligence, creativity etc.

These were the small objectives of the foundation of AI and how machines will stimulate like Humans in future. Artificial Intelligence needed lot of facilities to start with. Millions of dollars invested by US government to make the researchers visions true. But in the late 18th century there were lack of sufficient powerful computing environments, high speed and no huge amount of data available on that time, this was the reason AI came into halt.

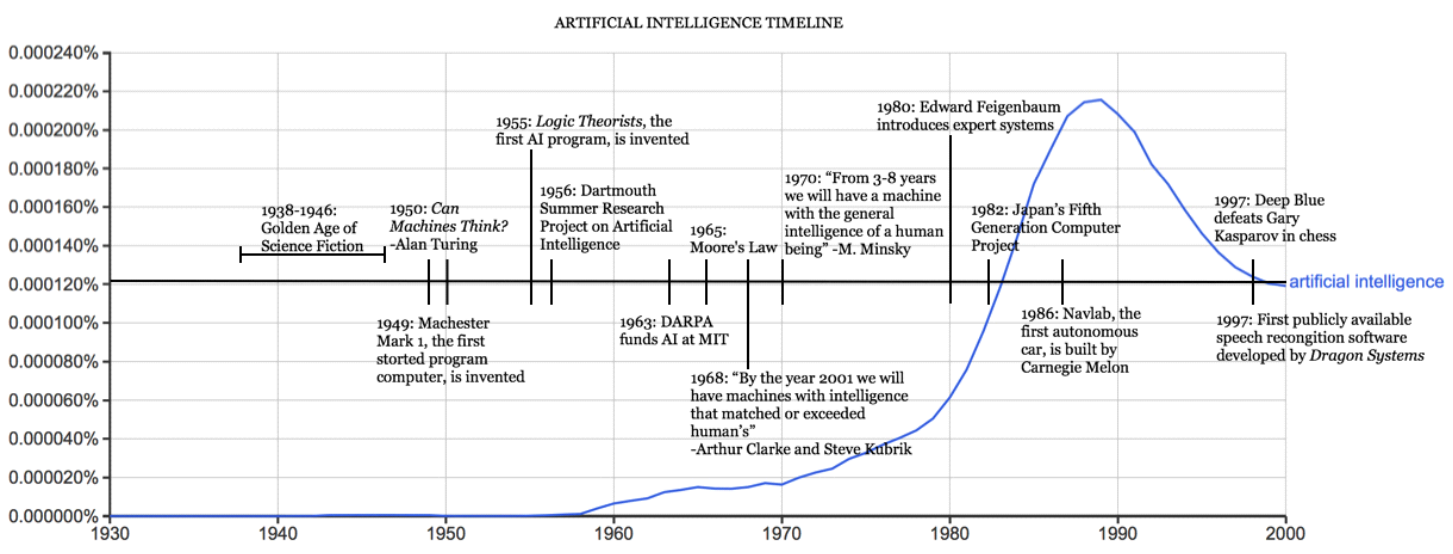

In the 1980's the term "deep Learning" technique proposed by John Hopfield and David Rumelhart,this technique allowed computers to learn using experience. Then the other familiar terms viz. natural language processing and expert systems which mimicked the decision-making systems same as human. After that Expert system technique heavily opted by industries and then the Japanese Government understand the importance of virtual intelligence system concepts and they funded heavily on expert systems and other AI related projects as a part of their Fifth Generation Computer Project(FGCP).During the success and setbacks roller coasters sometimes the AI and its related terms funding stopped because of not meeting the expected outcomes but the vision of researchers not fell out. During the 20th century, AI thrived in the lack of government funding and public hype. The first landmark of AI achieved when the world chess champion and grandmaster Gary Kasparov was defeated by Deep Blue (A chess playing computer program by IBM).

Then in the same year Dragon Systems implemented their Speech Recognition software on Windows. After this big achievement, the AI moved its steps forward towards language processing systems and people started to believe that machines can handle this kind of tasks. In the late 1990s kismet, a robot head made at Massachusetts Institute of Technology by Dr.Cynthia Breazeal that can stimulate and recognize human emotions.

The enormous computing system and availability of huge amount of data and their proper 
management and the speed of networking worked as a boon for AI and machine Learning in the 21st century .The AI again came into existence with more development and advancement in this century.

\section{AI in Current Scenario:}

Today, AI is no longer a hidden or new technology for us that needs an introduction. We now live in the era of "Cloud Computing" and "Big Data",an era where no lack of massive amount of data or other sources to process the information through AI.Everybody in the world is somewhere connected with AI and it is affecting us on daily basis, whether it is your smart phones to which you can touch and talk to it,virtual assistants,robotic arms which are helping you to perform complex tasks in industries,getting recommendations of movies or series,or a simple vacuum cleaner available in our homes.Most of the things that you are able to see in your surroundings attached with AI and Machine Learning.In present as the world moves with fast pace towards new technologies and machine intelligence, the big technology companies such as Microsoft,Facebook,Google,Apple and IBM are heavily invested to explore AI applications and research.Even most of the prestigious universities have devoted a department for the AI studies.

As AI is becoming more and more popular nowadays the number of users and researchers are increasing side by side, the innovations relying on vision based on computer,Natural Language Processing and speech recognition system.AI is not only changing the traditional way of technology, but it is also changing the way of people to interact with technology. The AI applications will be going to be more advance and smarter in upcoming years. The applications which we are currently using are mainly distributed among 8 major domains as Education, Transportation,Safety \& Security,Workplace,Medical healthcare,Service robots,low resource community and
Entertainment.Although AI technologies have influenced us and will continue to influence on these domains in a different manner.Every domain has its own benefits and challenges,including the complexity of creating reliable and safe application based on the environment of that domain.In the last fifteen years, AI has evolved as a powerful tool that ease the complex tasks and in the next fifteen years, AI will promote vast fields of technological changes and will change the way of living of the people.

- The computer Science driving AI rapidly advancing not only from technological point of view but from social,legal and ethical perspective also.The development of technology brought enormous improvement in consumer and entrepreneurs.Technology in form Chabot,humanoid robot[Sofia], compete with humans to perform tasks. The line of reasoning led to phenomenon of Polarization technology used to replace workers who have less capability.AI makes its place in every industry and doing great job there with lots of improvementnowadays when world is fighting against covid-19 then the robots in healthcare demand increased.A number of applications of $\mathrm{AI}$ is being used by majority for a small tasks to even big and complex tasks such as Email Filtering is something every user of email uses for filter spam mails,credit card fraud detection is helping people to protect them from frauds and scams related with banking,face detection technique helps in maintaining security and privacy.In 2019 medicine and AI researchers find out onset of breast cancer can be detected accurately and help doctor in identifying malignant cells. This help in making optimal treatment plan proposed. 


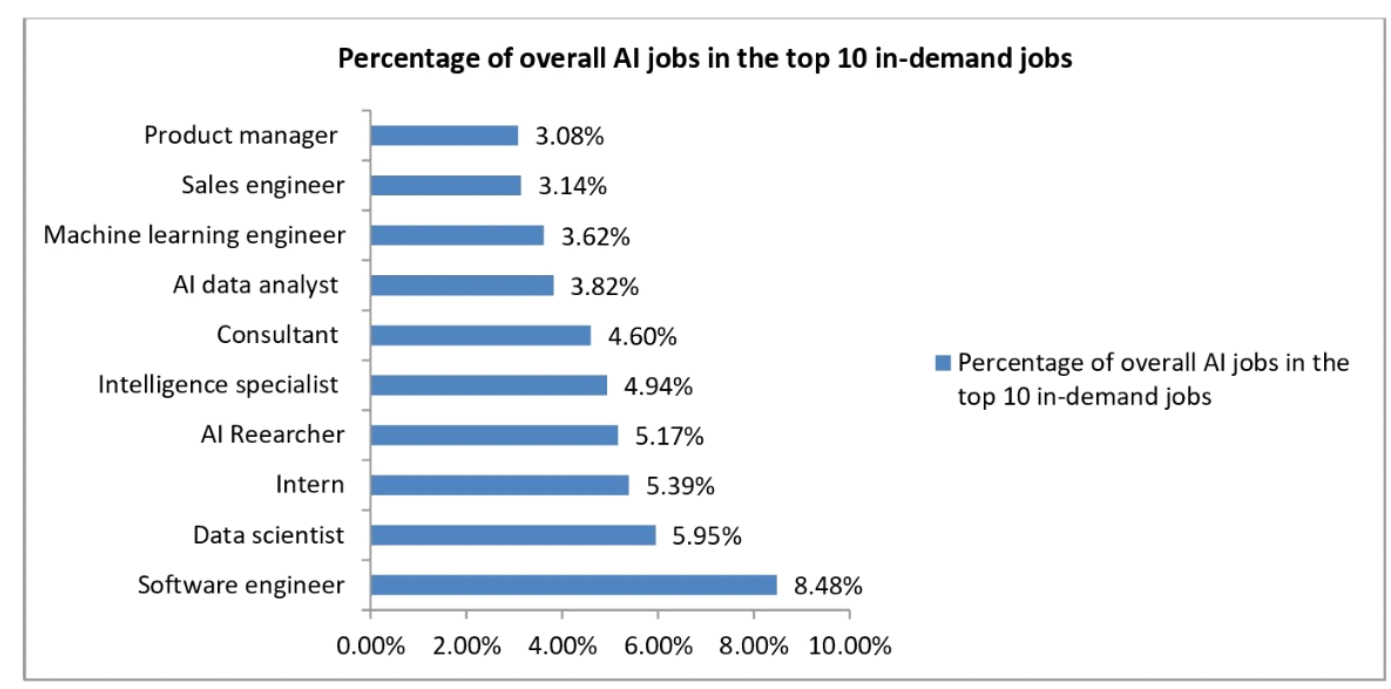

The graph above shows the current scope of AI related jobs in every field and the list is the top 10 most demanding jobs.

Rise in different technologies minimize cost and increase revenue and optimize work.It help in doing Technical support and personal recommendation help increasing sales and also help in advertising,productivity,consumption,choosing raw material and device so on.

\section{AI in Future(in 2030): -}

Nowadays AI are often observed altogether around people sleep in and humans are witnessed in rate of growth AI by identifying cat videos to self-driving cars. Artificial intelligence has progressed rapidly and it's not an idea from imagination or any Hollywood sci-fi movies, but we will better feel it actually by seeing robots in several industries and straightforward voice automation in homes. The future of AI is not just limiting robots and driverless cars, but it will go to beyond imagination of general public. The future of Artificial intelligence will be more focused on making machines super intelligent and can bring an environment human and machine friendly. Artificial Intelligence will be translating languages by 2024 better than humans, will write school essays by 2026 , will be selling goods by 2031 , write bestselling books by 2049 and can ready to conduct safe surgeries by 2053.This statement is predicted by scientists at the University of oxford after a research on AI and its Future.

There is little question that AI will become an integral part of our lives reaching the human competency as super-intelligent. You may assume a number of the examples by own that how AI will impact us in future by changing the pattern of our lives like your orders will be placed at your doorsteps within minutes after placing order through flying drones, the appointments will be booked by voice assistants, flying cars are going to be destination, your attendance and presence will be mark through facial recognition, home and repair robots will available at your homes for the household chores and lots of other examples you can assume with the assistance of intelligent systems. But the advancements of AI are going to be quite just simple tasks, but that advancement is way off now.

Some predictions regarding intelligent way forward for machines are-

More than electricity,AI goes to vary the planet quite anything within the history of mankind. -AI oracle and venture capitalist Dr Kai-Fu Lee,,AI Oracle and venture capitalist,2018.

By 2030,most social situations will be facilitated by bots-intelligent seeming programs that interact with us in human-like ways. -Judith Donath, of Harvard University Berkman Klein Center for Society \&internet

\section{AI and automation drilling deeper into every} business.-Forbes 
In subsequent 5 to 10 years $A I$ is going to deliver numerous improvements within the quality of our lives. -Mark Zuckerberg,CEO\&Founder of Facebook

From data-driven market to tools for entrepreneurs, the success of AI will only be measuredin terms of the worth it create for Human lives. The fear of AI will overpower and control the humans are high then it is important to design AI systems to form people enable to know those successfully, participate in their use and have trust on those. As AI will be going to contribute tonswithin the change of economy also because the society expect for considering machines as super intelligent or machines can exceed from human intelligence is a long distance to cover but what changes will takes place in our lives after 10 years is the main concern. As AI technology already infuse with our lives, as they become the central mode of attraction within the society, the field is shifting from simply build systems that are simply intelligent to putting together systems which are human friendly, human aware and most important trustworthy. The AI revolution has been fueled by several factors like Machine learning which is more mature and suitable now with the support of cloud computing resources and web-based data gathering. The subset of Machine Learning, "Deep Learning" is additionally moved forward with the assistant of adaptive artificial neural networks. The concept of AI in future would be "Less Artificial, More Intelligent".

\section{Overall Future AI Research Domains By 2030:}

Although there are numbers of domains for AI to search for but the main priorities are on basic fulfillments of the society and for those sectors from which most of the growth of the country and people associated with. In this section How AI research and implementations as well as its impacts and challenges in eight domains is described. The major analysis will impact on the lifestyle of a city of North America in next fifteen years will predict as AI is already beginning to pervade everyday life, and how those transformations are likely to grow by 2030 .

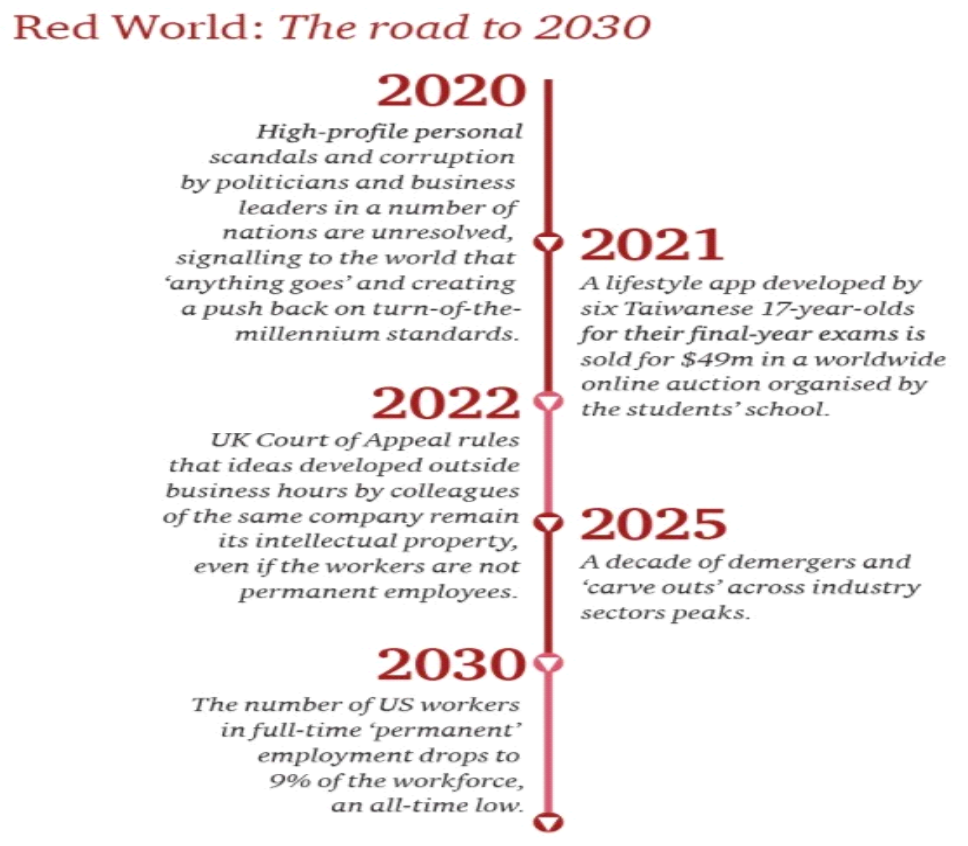

The risk predicted by PwC Workforce of the Future Report. 
Blue World: The road to 2030

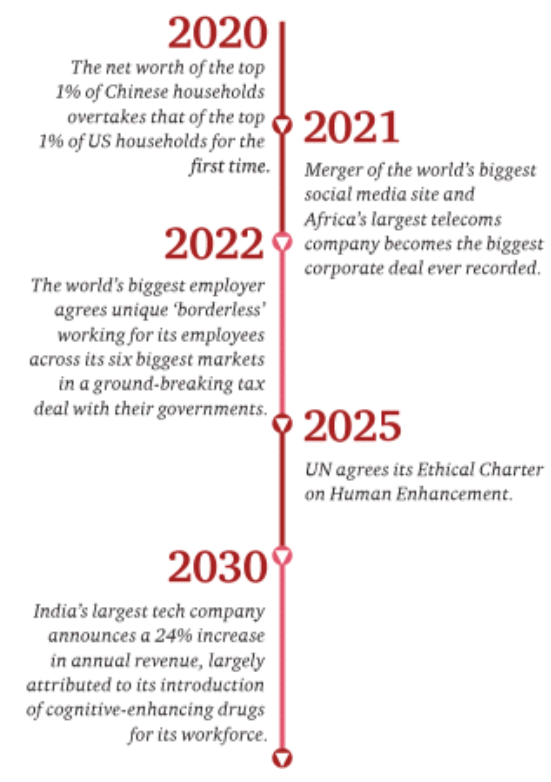

PwC Workforce of the Future Report with Optimistic Way.

\section{Transportation:}

Transportation is the most important domain in which general public will ask to trust the safety and reliability of an AI system during critical cases. As driver less cars are already in the market then there is no doubt that autonomous transportation will be commonplace soon and the first interaction with humans with these AI systems will definitely be going to strongly influence the public's perception towards the intelligent machines. The transportation industry based on Artificial Intelligence is projected to grow during the forecast period at a CAGR of $17.87 \%$ and the expected market size from USD 1.21 Billion in 2017 is expected to grow to USD 10.30 Billion by 2030 . In future $\mathrm{AI}$ in transportation industry impact on

- Autonomous Vehicles: Self -driving cars and taxis have already started operating in Tokyo. Also, autonomous trucks are also going to come in the market by 2030 .

- Delay Predictions: With the help of computer vision and leveraging data lake technique, exceptional service can offer by transportation companies to passengers in cutting down passengers wait times and enhancing their journey experience.

- Traffic Management: AI will not only help in reducing congestion of unwanted traffic but also improve in reducing wait times and road safety system.

- Drone Taxis: This is something that will far way to achieve in next 10 years but the concept of pilot-less helicopters definitely present a sophisticated and unique way to organizing and maintaining the traffic congestion and carbon emissions.

As in today Google's autonomous vehicles and Tesla's semi-autonomous cars are driving in streets ,Google's self-driving cars which have reported more than 1,500,000 miles $(300,000$ miles without accident), are completely autonomous while Tesla has widely released their semiautonomous cars with human drivers expected to stay engaged to handle any critical situation. It is predicted through a research that in nearfuture,sensing algorithms will achieve the capabilities of super-human performance required for driving. And this adoption of self-driving capabilities won't be limited only to personal transportation, but we will see in the future flying vehicles, remotely controlled delivery and selfdriving trucks and drones. A major force towards self-driving cars likely On-demand transportation services.

\section{Healthcare:}

Already AI and Machine Learning is playing vital 
role in healthcare sector like for detecting tumors, predicting illness changes in patients as well as robots in healthcare is helping nurses to bring the medicines for the patients during COVID period. So, healthcare is the long viewed promising domain and according to a research, nearly $86 \%$ of the mistakes in the healthcare industry can be prevented by opting AI based systems. The future of AI based healthcare systems could improve the health related outcomes and quality of life in coming years for millions of people but the major factor is to gain trust of people related with health industry such as doctors, nurses and especially patients.

There is a great future of AI applications with vast jobs roles but to achieve that advancement in medical science, all these will take a long time. Below are some impacts of AI on healthcare sector by 2030 -

- Healthcare industry will achieve smart patient monitoring systems, surgery assisting healthcare robots, mobile driven robotic consultants and intelligent system to reveal patterns in disease and their aid treatment by accessing multiple sources of data.

- By 2030,AI systems will be able to predict the risk of certain disease of an individual and accordingly suggest preventive measures.

- Not only related with medications AI will be able to maintain the management of patient and doctor meeting time and reducing the waiting time of patients andwould improve the efficiency of health systems.

\section{Public Security and Safety:}

The security and Safety of public is the major factor of whatever technology exist in the market. By implementing different types of AI based applications for the security and safety of public, it can be seen that people would start trusting on AI based security applications. By 2030, a city of North America is going to rely heavily of AI technologies, research from Stanford University predicted this. Even today the cameras in different areas of the city are helping to catch thieves and criminals with ease.

The future will be impacted by AI for public safety and security as-

- Many cybercrime industries will create applications based on AI to prevent from malwares and viruses.

- The AI based facial recognition and speech recognition system will improve the efficiency of the administrative systems and reduce the crime rates of the world.

- Advance intelligent systems[intelligent robots] will improve the overall security and safety concerns of public by protecting them from fraud and sudden accidents.

\section{Home Service Facilities:}

With the advancements of AI based applications in different domains, the Home service facilities will also be going to affect. If the advancement related with AI in this sector discussed then one can easily see the pervading of $\mathrm{AI}$ in our lives from the past fifteen years in the form of robots. Vacuum cleaner available in our homes are the most practical example of this. In the next fifteen years, AI and related technologies will going to become more digitalized by creating more reliable and safe applications. A typical city of North America is going to fully rely on AI based technologies in the next ten years.

The Home and service facilities will have influence by AI are as follows-

- The North American city will have special purpose robots by 2030 for tasks related with home and service like you will see waiter robots in the restaurants, robots for office cleaning and delivering packages.

- Although in the coming years, home robots would become common but the high costs and technical constraints will continue to limit the commercial opportunities for future. 


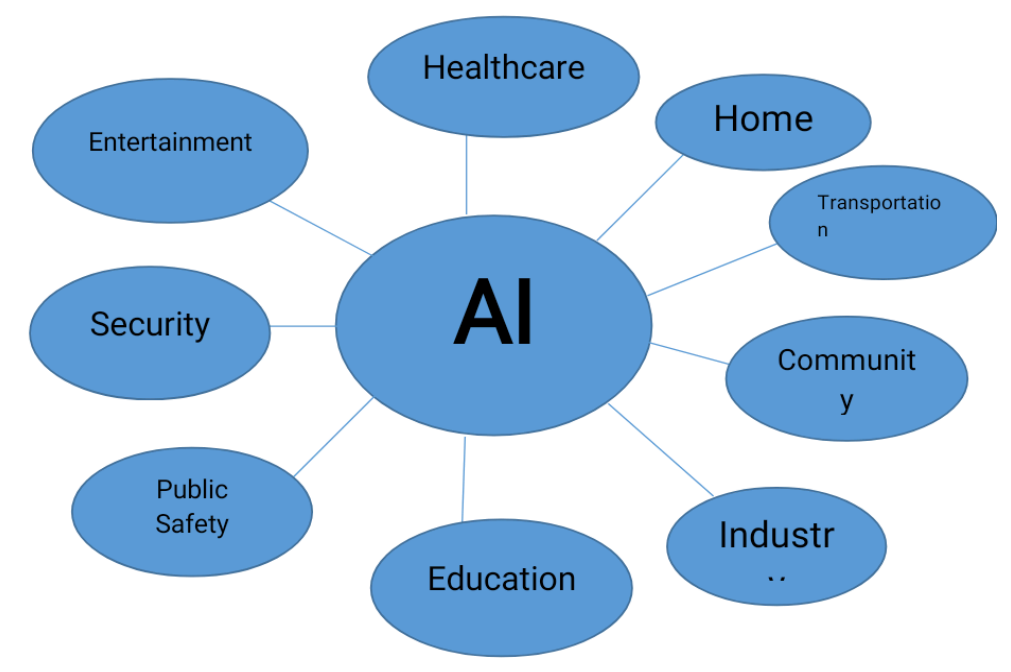

\section{Education:}

The technology is usually a boon for the education within the last century. The more advancement of technology will lead to facilitate the education policies. The AI based robots would be a popular factor of education although education always need an active participation of student and teacher. Smart classes and applications based on intelligent systems will forward the education policies towards the digitization.AI facilitates in automating complex administrative tasks related to both academic institutions and professors.AI in education will help:-

- As in present the value of time is more and teacher are wasting their most of the time by evaluation test sheets, assignments and grading homework and giving feedbacks and responses to the students but in the next ten years, AI based applications will replace this traditional system and would help in evaluating the tests and giving the unbiased responses to the students with cost effectiveness

- For making interaction between students and teachers, AI opted institutes will have more opportunities to make the learning virtual and fun.

\section{Low-Resource Communities:}

Growth doesn't mean for a particular sector or community, the overall growth only considered when it impacts on every part of the society.
Economic growth of AI will be predicted to increase at a rapid rate by 2030 but the success of AI will be considered when it will influence the all communities of society.AI has more opportunities to improve the conditions of people in low resource communities.

- AI based applications would easily predict the needs of low resourcecommunities and will improve their way of living.

- Drones will be able to deliver extra foods of restaurants, community centers and food banks to the people in needs. The low resource community always have risks of spreading number of diseases, with the help of AI in healthcare system, the application can easily predict the chances of spreading community disease.

\section{Entertainment:}

Entertainment is the actual source which had given the birth of imagination related with flying vehicles, humanoid robots and autonomous infrastructure. With the increment of internet users in the last 20 years, no one can imagine a life without it.Today social media has a major importance in our lives such as Instagram, Facebook, Twitter and so on. In the coming years the entertainment industry will be going to influence deeply: -

- The AI based entertainment industries will be more personalized, digitalized and would be with less regulation.

- The Gaming industries with the help of 
intelligent systems will be really going to the next level such as 3D gaming system and playing with robots would be more fun.

- In future more sophisticated apps and tools will be available to ease the production of high-quality content.

\section{Employment and Workforce:}

Artificial Intelligence is a rapid advancing form of technology and researchers have predicted that it will be going to reshape the US employment factor soon. However, economists have also shown their fears with the advancement of AI in workplace. Labor will become less important and workers will be replaced by machines with automation and digitalization but what about the workers who wants a job and new industries won't use everybody, noted it in 1952, Wassily Leontief economist, Nobel Prize Winner, 1973.

As AI has both good and bad impact on the society in nearby future Optimistic predicts that AI will may displace the jobs but it will create more jobs than it displaces as well as the costs will cut by 30 $34 \%$.

- Economists has fear regarding job loss by opting AI based technologies but according to a report, Future of Jobs by World Economic Forum, AI will likely to produce
58 million new AI based jobs by 2022 and there is an excellent chance that AI will better perform most of the mental tasks compare with humans but it will not take away the jobs.

- The project and research based on $\mathrm{AI}$ is in progress by big technological companies Google, Apple, Microsoft.Every companies motive is to build something that will actually help humankind with advancement. Tesla is working on neural AI based chip that will help those people who are mentally disturbed to communicate properly.

- Central city of North America in between 2018 to 2023 is projected to the largest banking system market of AI, by IHS Markit,Artificial Intelligence in Banking Report. The AI will increase the business value from \$14.7billion in 2018 to nearby $\$ 79$ billion in 2030 .

The AI innovative power are going to bring to financial services to be transformative, said by Tait,Principal Analyst at IHS Markit.

According to a survey from IHS Markit's report, AI in banking will increase the global business value nearly $\$ 300$ billion by the end of 2030 .

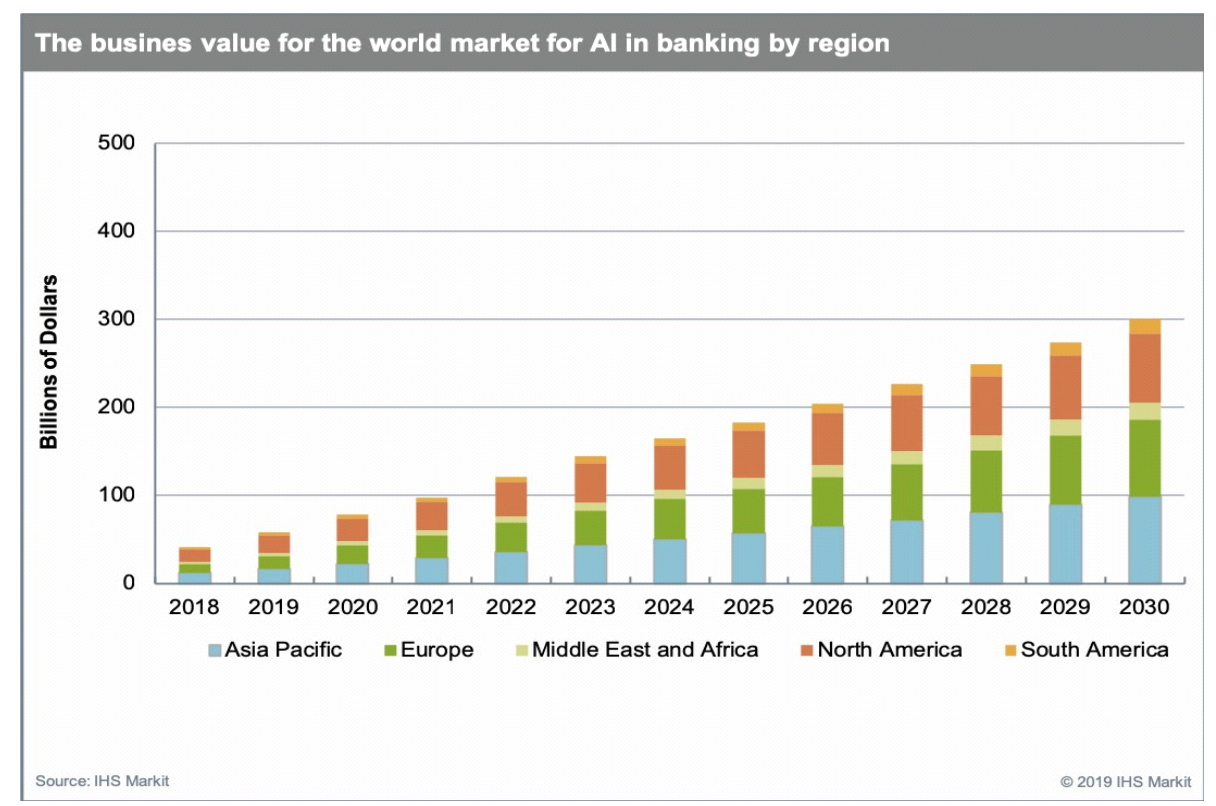

Report By IHS Markit Survey 


\section{Below is the comparison chart between AI based implementation Now(2020) and in Future(2030):}

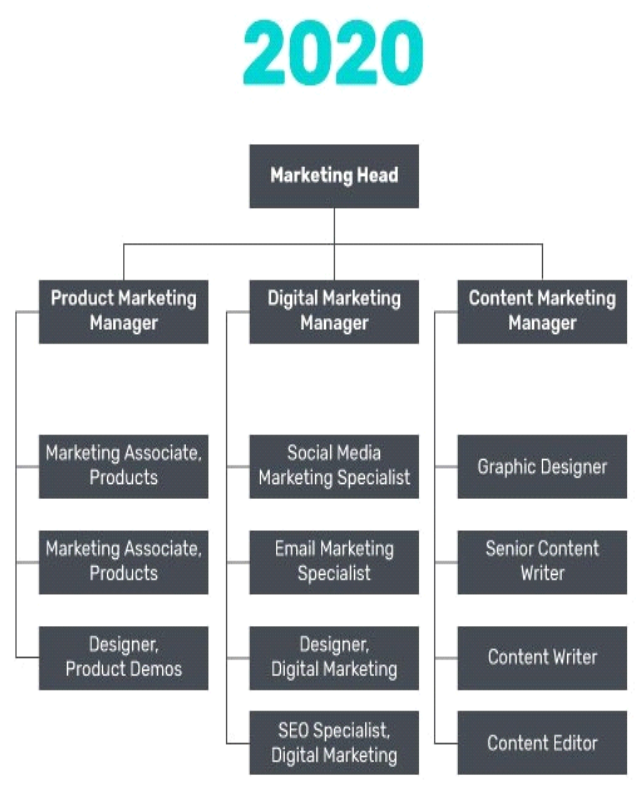

\section{DARK Sides and Challenges of AI:}

Humankind always been a witness of AI and its growth, humans have shaped and adapted to new technology throughout history.AI has covered a long journey from last century and also it has to cover a long way to achieve an environment of automation that is truly based on super intelligent system .Within near future, AI is going to affect on the way we live from societal, legal to economic aspects. The Fear that AI will overtake the jobs and will fully control the Human is the

biggest challenge in the success of Artificial Intelligence. According to different-different researches ,most of the intelligent minds have predicted their views on How AI will be going to influence our lives in Future? Predictions of some great minds are as-

A vast range of efficiency optimizations are going to be driven by AI, but it'll also enable arbitrary penalization and discrimination of people like performance assessment, job seeking and insurance."-Andrew McLaughlin, executive director of the Center for Innovative Thinking at Yale University.

AI may be a tool which will be used by humans for performing all kinds of works including the pursuit of power. But Unfortunately, AI are going to be

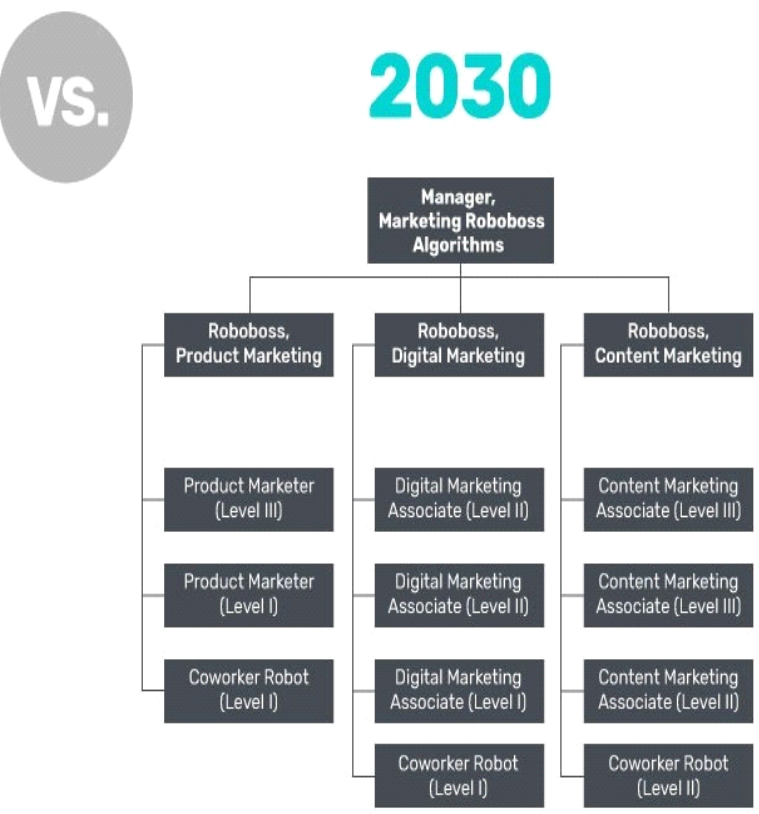

utilized in ascertain trend lines that will create instability and abuses of power. In example of climate change then AI will be used in harmful ways in order to create geopolitical crisis-Danah Boyd, Principal Researcher for Microsoft and president \& Founder of Data \& Society Research Institute.

By 2030,AI are going to be more likely used as a weapon to kill people and to fight wars that we will currently do-Simon Biggs,Professor of Interdisciplinary arts at the University Of Edinburgh.

Artificial Intelligence will still concentrate wealth and power within the few big monopoly's hands supported U.S and China. Most of the part of world and people are going to be worse off-Mark Surman,Executive director of Mozilla Foundation. According to a report generated by Mckinsey,By2030,some occupations will see significant declines, Around 400 million workers(or $15 \%$ of the global workforce)could be displaced by automation. 
Below is the McKinsey report on the jobs that will lost during in 2030.

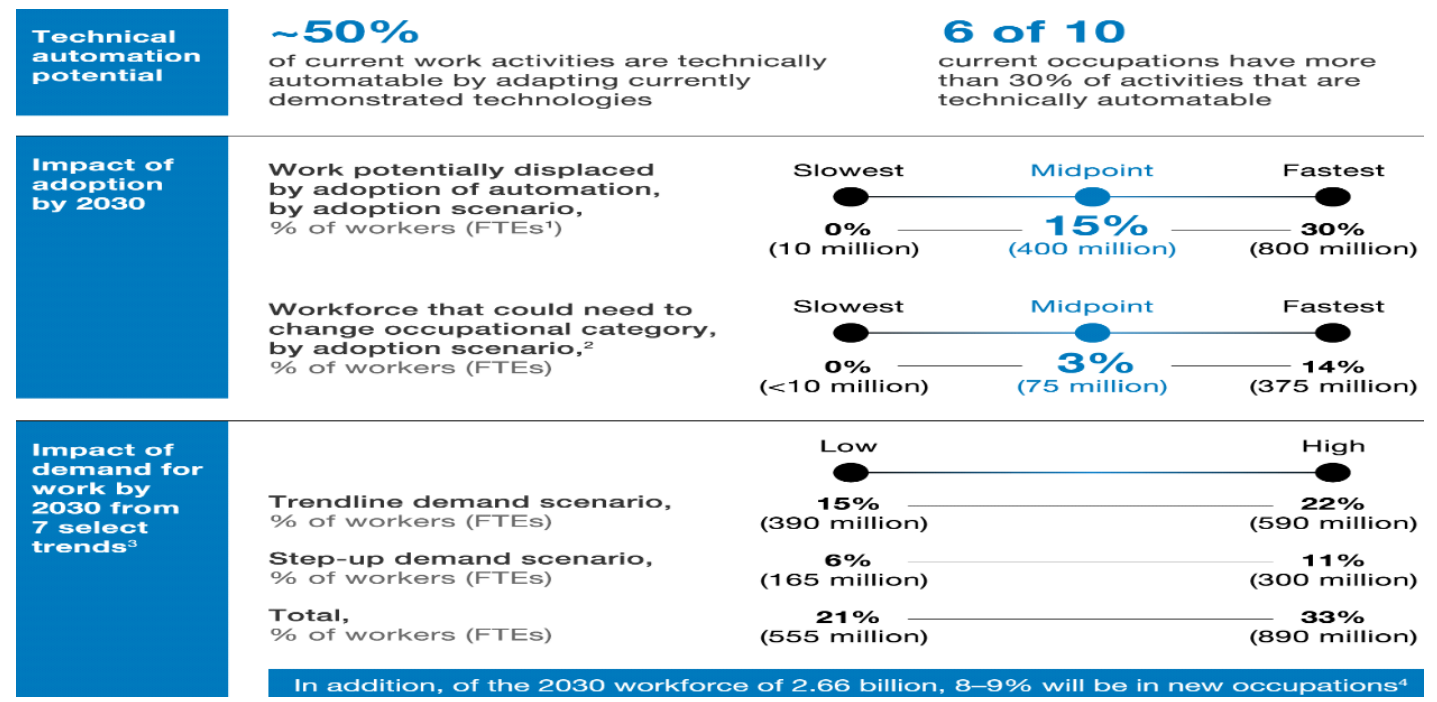

Fears of AI is somewhere will have faroff in future but some challenges that will affect the AI implementation are-

- High cost and more power will be the main cause of disturbing the proper implementation of Artificial Intelligence based system.

- Some challenges include who will be responsible for autonomous cars accidents.

- High skills will require to control AI driven system and the skills need to be updated according to change in technologies from every next year(maybe).

- Building trust on Intelligent machines of public would be a major part of influence. Trust deficiency will lead to halting the growth of Intelligent machines and automation.

\section{Conclusion:}

AI has the capability of transforming global market and economy via scientific research \& knowledge, innovative skills and entrepreneurial activities. The growth of AI in the last two decades have proven this point and now in this era we all are living, the role of AI based applications have more concentration for making our lives better and fast. Machine intelligence and critical thinking like human help many applications specific project. Visionary research in AI help in its progress. A distinct strategy is required to associate ethical and legal challenges of AI to make society benefitted from evolution of AI. Machine Intelligence and its diverse

application leads to create unbelievable gadgets that will be helpful for society to do complex tasks and solve complex problems in day to day life. Artificial Intelligence brings science fiction into practical reality sustain funding by government and responsible investment will transform future of our society, economy, business, life and everywhere.

Table :- The details of Skills ,Related jobs, salary in US (in USD)

\begin{tabular}{|l|l|l|l|}
\hline S.No. & Skills & Related Jobs & $\begin{array}{l}\text { Approximate U.S } \\
\text { Salary( in USD) }\end{array}$ \\
\hline 1 & $\begin{array}{l}\text { Machine learning, } \\
\text { Python, Data Science, } \\
\text { AI }\end{array}$ & $\begin{array}{l}\text { Machine learning } \\
\text { Engineer }\end{array}$ & 182000 \\
\hline
\end{tabular}




\begin{tabular}{|c|c|c|c|}
\hline 2 & $\begin{array}{l}\text { Development, } \\
\text { Amazon Web } \\
\text { Services ,Linux }\end{array}$ & $\begin{array}{l}\text { Cloud Architect, } \\
\text { Solutions Architect }\end{array}$ & 107750 \\
\hline 3 & $\begin{array}{l}\text { Solution Architecture- } \\
\text { python }\end{array}$ & $\begin{array}{l}\text { Site Reliability } \\
\text { Engineer }\end{array}$ & 107750 \\
\hline 4 & $\begin{array}{l}\text { Data Science, Data } \\
\text { Mining, Data } \\
\text { Analysis, Python } \\
\text {,Machine Learning }\end{array}$ & $\begin{array}{l}\text { Data Scientist, } \\
\text { Engagement } \\
\text { Manager }\end{array}$ & 130000 \\
\hline 5 & $\begin{array}{l}\text { Cloud computing } \\
\text { Enterprise Software, } \\
\text { Software-as-a-service, } \\
\text { Business Analysis }\end{array}$ & Solutions Consultant & 110000 \\
\hline 6 & $\begin{array}{l}\text { Analysis, Software } \\
\text { Development, } \\
\text { Business Analyst }\end{array}$ & $\begin{array}{l}\text { Scrum Master, } \\
\text { Information } \\
\text { Technology, Cad, } \\
\text { Product owner }\end{array}$ & 113750 \\
\hline
\end{tabular}

\section{References:}

1.Notes from the AI frontier: Modeling the impact of $\mathrm{AI}$ on the world economy,2018,Jacques Bughin, Jeongmin Seong, James Manyika, Michael Chui, and Raoul Joshi, https://www.mckinsey.com/featuredinsights/artificial-intelligence/notes-from-theai-frontier-modeling-the-impact-of-ai-on-theworld-economy

2 .Lynch S (2017) Andrew Ng: Why AI Is the New Electricity. Insights by Stanford Business. https://news.stanford.edu/thedish/2017/03/14/. Accessed 5 October 2018

3 .Pamela McCorduck, Machines Who Think: A Personal Inquiry into the History and Prospects of Artificial Intelligence, 2nd ed. (Natick, MA: A. K. Peters, Ltd., 2004; San Francisco: W. H. Freeman, 1979), Citations are to the Peters edition.

4."Intelligent transportation system," Wikipedia, last modified July 28, 2016, accessed August 1, 2016,

https://en.wikipedia.org/wiki/Intelligent_trans portation_system

5. "Google Self-Driving Car Project," Google, accessed August 1, 2016https://www.google.

com/selfdrivingcar/. 33 Molly McHugh, "Tesla's Cars Now Drive Themselves, Kinda," Wired, October 14, 2015, accessed August 1, 2016, http://www.wired.com/2015/10/tesla-self- driving-overair-update-live/

6.LeighAnne Olsen, Dara Aisner, and J. Michael McGinnis, eds., "Institute of Medicine

(US) Roundtable on Evidence-Based Medicine," The Learning Healthcare System: Workshop http://www.ncbi.nlm.nih.gov/books/NBK5350 $0 /$.

7. Peter Neffenger, "TSA's 2017 Budget-A Commitment to Security (Part I)," Department of Homeland Security, March 1, 2016, accessed August 1 , 2016 , https://www.tsa.gov/news/testimony/2016/03/ 01/hearing-fy17-budget-requesttransportation-security-administration.109 Crawford, "AI's White Guy Problem."

8.Artificial intelligence in healthcare: past, present and future,Fei Jiang1, Yong Jiang2, Hui Zhi3, Yi Dong4, Hao Li5, Sufeng Ma6, Yilong Wang7, Qiang Dong4, Haipeng Shen8, Yongjun Wang9, https://svn.bmj.com/content/2/4/230.abstract

9. Future Progress in Artificial Intelligence: A Survey of Expert Opinion, https://link.springer.com/chapter/10.1007/9783-319-26485-1_33

10.Global Business Value of Artificial Intelligence in Banking to Reach $\$ 300$ Billion by 2030 , IHS Markit Says, https://benchmarking.ihsmarkit.com/611814/g lobal-business-value-of-artificial-intelligence- 
in-banking-to-reach-300-billion-by-2030-ihsmarkit-says

11. Artificial Intelligence Future - How it will affect our lives in the next decade?, https://in.springboard.com/blog/artificialintelligence-future/\#

12.Expert Predict When Artificial Intelligence Will Exceed Human Performance, https://www.technologyreview.com/2017/05/3 1/151461/experts-predict-when-artificialintelligence-will-exceed-human-performance/

13 .Is Artificial Intelligence The Future Of Education?, https://www.raoconsultants.com/artificialintelligence-future-

education/\#: :text=AI\%20has\%20potential $\% 2$ 0in\%20automating,students\%20one $\% 2$ Don $\%$ 2Done

14 .https://courses.cs.washington.edu/courses/cse p573/10wi/final-lecture.pdf

15. AI in 2030: will it have empowered humans or destroyed us? ,https://www.scmp.com/lifestyle/article/21 79026/ai-2030-will-it-have-empoweredhumans-or-destroyed-us-experts-weigh

16. One Hundred Year Study on Artificial Intelligence(AI 100), https://ai100.stanford.edu/

17. Artificial Intelligence and the Future of Humans,December 2018 , https://www.pewresearch.org/internet/2018/12 /10/artificial-intelligence-and-the-future-ofhumans/

18. The present state of Artificial Intelligence, 2019,

https://www.analyticsinsight.net/present-stateartificial-intelligence/

19. Can Machines Think?,Rockwell Anyoha, http://sitn.hms.harvard.edu/flash/2017/historyartificial-intelligence/

20. Artificila Intelligence and its Applications in Different

Areas, https://www.engpaper.com/artificialintelligence-research-papers-2012.htm 